\title{
Evaluation of the Time allocation for Work and Personal Life among Employed Population in Lithuania from Gender Perspective
}

\author{
Zigmas Lydeka, Viktorija Tauraite
}

\author{
Vytautas Magnus University \\ S. Daukanto st. 28, LT-44246, Kaunas, Lithuania. \\ E-mail.zigmas.lydeka@vdu.lt; tauraiteviktorija@gmail.com
}

cross $^{\text {ref }}$ http://dx.doi.org/10.5755/j01.ee.31.1.23056

\begin{abstract}
In this paper, researchers examine the allocation of time for personal life and work. In fact, this phenomenon is particularly relevant in the 21 st century because employed people are most commonly faced with many issues related with work-life conflict or work-life imbalance. This kind of problem can occur for both men and women, yet it is noteworthy that the time use features can naturally differ between both sexes: women and men. For this reason, focus of this study lies on the evaluation of work-life balance between employed Lithuanian men and employed Lithuanian women. Firstly, this article analyses the theoretical background of time allocation for personal life and work. Secondly, the methodology of empirical research is presented and substantiated. Although the research was conducted in Lithuania, the methodology can be applied in another country than refer to a nationality. The results of the empirical study have shown that there are some differences in time use between both sexes: women and men. Men spend relatively more time on sleep, other physiological needs (eating; personal hygiene etc.), science / studies, leisure (in the narrow sense), and traveling than women do. On the other hand, women spend relatively more time on paid work, housework and child care, and other activities of life. It should be emphasized that a significant difference in leisure time (in the narrow sense) use between men and women has been identified. This gives the opportunity to predicate that men spend more time in leisure (in the narrow sense) than women do.
\end{abstract}

Keywords: Employed Persons; Men and Women; Time Allocation; Time for Personal Life; Time for Work; Labour-Leisure Model.

\section{Introduction}

Time is a specific economic resource, which is limited and needs to be rationally balanced between personal life and work. The time allocation for personal life and work represents the behaviour of employed person in labour market, their social behaviour, priorities (in the context of time allocation), differences between different market participants (employee; employer and differences of each group), etc., all of which are relevant in the assessment of this century's labour market problems. In this case, the subtleties of time use between genders can be explored by identifying the main differences and similarities. This kind of analysis provides an opportunity to evaluate and better understand behaviour of men and women in time use. This awareness is important in studying the need to balance work and private life. Furthermore, this is becoming particularly relevant in contemporary society. This situation may be due to the fact that it is often difficult to balance conflicting goals such as the need for self-realization (individually and in a group) in workplace, desire to have sufficient monthly wage, the need to spend enough time on private life. These problems are common to employed population in general and to men and women individually. Thus, it is meaningful to analyse the use of time between employed women and men in order to know and evaluate the behaviour of these target groups and their habits in terms of time allocation.

Noteworthy, both men and women often seek to balance their time between life and work. Nonetheless, the imbalance between work and personal life is a particularly acute problem in the modern society facing men and women. This problematic area encourages researchers to continue to explore the time use by analysing and evaluating the time allocation features related to gender.

As the authors of Lydeka \& Tauraite (2018) found out, Alesina et al. (2006), Caragea (2009), Aguiar \& Hurst (2007), Krueger \& Mueller (2012), Fortin et al. (2010), Hamermesh \& Stancanelli (2015), Jankiewicz (2015), Colella \& Van Soest (2013), Sappleton \& Lourenco (2016), Ryu (2016) etc. investigate object of time use for personal life and work in different aspects. Yaniv (2011), Ratzel (2009) and other researchers highlight the lack of papers about allocation of time at two main points: at empirical and theoretical levels in the economic context. The studies about time allocation between women and men are important too.

It is logical that there are some differences in time allocation between both sexes: women and men, as this is often associated with different priorities, goals, etc. On the other hand, presenting differences, similarities, trends, and insights about time allocation to work and personal life between men and women is beneficial. All of this allows for a broader assessment of existing gender differences and conclusions in various areas. Therefore, considering the relevance of this issue in contemporary society, it is important to continue to explore time use. For this reason, the authors of the article conducted an empirical study about time allocation of employed Lithuanian population. Thus, the scientific research problem is what is the content of the time allocation object in a twenty-four hour period between men and women, and what are the main differences and similarities between the studied populations? 
The aim of this research is to analyse main theoretical and practical assumptions of the content of the time use phenomenon of employed population and to empirically investigate differences and similarities between employed men and employed women in seeking to balance work and life. Tasks of the research: to review theoretical aspects of time use for personal life and work; to justify the methodology which is used in this study; to determine the main principles of time use between employed men and employed women in Lithuania in terms of time allocation, and to present the most important similarities and differences between the research groups; to summarize the results of the research presented. The article was based on four methods: comparative analysis of scientific literature, time diary method, a questionnaire, and correlation analysis.

The structure of this paper consists of three main parts. Firstly, the most important theoretical principles of the time use for life and work are determined. Secondly, the methodology applied for empirical research is presented and substantiated. Thirdly, the empirical research and results of it about the time use between employed men and employed women in terms of time allocation and the most important aspects of this, are further elaborated and summed up.

\section{Theoretical Background of Time Allocation for Work and Personal Life}

Labour-leisure (or labour-personal life; further labourleisure (personal life)) model characterizes the behaviour of labour supply participants (i.e. employees) in the labour market, when the time of individuals is divided into these separate parts: leisure and work (Fortin et al., 2010; Kabukcuoglu \& Martinez-Garcia, 2016; Kalenkoski \& Hamrick, 2013, etc.). Further in this article is presented and explained the theoretical assumptions about the main areas of time allocations and the main principles of it.

Working time in this paper is understood as paid work time. This definition is used such researches as Aguiar \& Hurst (2007), Manski (2014) and other authors. Of course, time for work can be regulated respectively, according to particular country, state and / or its belonging to organizations, unions (Lee et al., 2007). So, this aspect is important too.

Leisure time in literature can be determined as the other remaining time of the day, i.e., unpaid working time (housework; childcare etc.), including many forms of leisure activities (Aguiar \& Hurst, 2007; Manski, 2014, Douglas \& Morris, 2006, etc.). So, leisure time can include such areas of time: (1) time spent with family; (2) time spent for social needs; (3) time spent for traveling; (4) time spent for sports, etc. (Douglas \& Morris, 2006). In summary, this kind of leisure time definition is determined in the broad sense. On the other hand, the leisure time can be identified in the narrow sense too. Aguiar \& Hurst (2007) described leisure in narrow sense as a unison of these four elements: (1) the entertainment; (2) the social activity; (3) the relaxation; (4) the active leisure. The other definition of leisure time is described by Cavagnoli (2008). Researcher indicates leisure time as time left from total time (e.g., time of day, that is, twenty-four hours), minus time spent on unpaid work (e. g. housework and childcare) and paid work (i.e. working time).
Scientists Wei et al. (2009) present other classification of leisure time, which consists of three elements: (1) leisure time for learning; (2) necessary leisure time (time for housework; relaxation, etc.); (3) nice leisure time (time for sports; for traveling; for fun, etc.). Furthermore, another leisure time breakdown is presented by Hawrylyshyn (1977). Researcher points out that the daytime should be divided into these parts: (1) biological needs (e.g., sleep; personal care, etc.); (2) work (i.e., paid labour market); (3) productive activities (e.g., housework; childcare; learning, etc.); (4) leisure activities (e.g., entertainment; recreation, etc.). A more detailed analysis of leisure time was conducted by Lydeka \& Tauraite (2018). So, the literature review of leisure time shows that there is still a wide spectrum of the leisure time definitions. In this paper the definition of leisure time is understandable in the broad sense.

So, the theoretical review has shown that time of the day can be divided into two main elements: (1) working time; (2) time for personal life. This categorization is used by researchers such as Douglas \& Morris (2006), Forris (2015), Yaniv (2011) and other scientists. This classification of time is used in this article too. So, in this paper the time for personal life is understood as time allocated to all activities (except time for paid work). In this case, there is logical connection between the time spent on personal life and leisure time (broad sense). These definitions are synonymous in the context of time allocation. This assumption is used in this article too.

Further in the theoretical part of this article it is appropriate to introduce model of labour-leisure (personal life) and related principles. The main concept of labourleisure (personal life) model properly describes this situation: rational person needs to maximize benefits by choosing these items: work and consumption (Myck \& Reed, 2006; Sendi \& Brouwer, 2004; Manski, 2014; Dagsvik et al., 2012, etc.). In other words, an employed person seeks to choose the best possible time allocation combination between time for leisure (personal life) time and time for work. This basic principle of the model is also emphasized by Lydeka \& Tauraite (2018).

The labour-leisure (personal life) model is based on three main constraints: (1) budget; (2) time; (3) environmental. In this study relevant is time constraint, but others of it in detail are analysed in paper by Lydeka \& Tauraite (2018). Time is a limited resource and can be explored in the context of a resource economy. This type of economy is being explored by Mezey \& Conrad (2010) researchers. The time constraint describes the structural classification of time into two parts: work activities and other non-work related activities (i.e., personal life; Becker, 1965). This condition can be normally integrated into the context of work-life conflict. For example, employed person who do not allocate time between private life and work properly, experiences a conflict of work and / or personal life. So, this is a negative consequence of time allocation imbalance. Moreover, there can be more negative impact of this situation on personal career, employee health (physical and psychological), work quality, personal relationships (social skills, etc.) and other problems (International Labour Office, 2011). The real situation and investigation of worklife conflict is presented by Laeeque (2014). Scientist analyses the Pakistan banking sector. The results showed 
that the work-personal life conflict also has negative impact on personal career opportunities and person's productivity.

So, the labour-leisure (personal life) theoretical model deals with the seek to maximize the benefits of time allocation of two parts (work time and personal life), when exist three main conditions (i.e., time, budget, environmental). In a practical way, the efficiency of labour-leisure (personal life) model also depends on gender and differences of it. For example, Bauer et al. (2007) points out that work-life balance is relatively simpler for men. This is probably due to the frequent stereotypical view in Europe that a woman should be responsible for the housework. Naturally, in this case, working women should have more difficulty in balancing work and life (Fernandez-Crehuet et al., 2016). Compared to men, difficulties in work-life balance for women may also be based on number of children in family. This fact is also underlined by OECD (2011), Fernandez-Crehuet et al. (2016) and other researchers. In other words, the assumption is that the greater number of children in family, the more time the woman spends on housework and childcare. All this ultimately has a negative impact on work-life balance. Therefore, the differences in time use between work and personal life can be influenced by gender, their different priorities, and similar aspects.

It can be concluded, that the optimal choice of time between personal life and work, allows employed person to avoid negative effects of work-life conflict.

Previously time allocation studies. Scientists (e.g., Aguiar \& Hurst, 2007; Caragea, 2009; Alesina et al., 2006; Fortin et al., 2010; Krueger \& Mueller, 2012; Colella \& Van Soest, 2013; Jankiewicz, 2015; Hamermesh \& Stancanelli, 2015; Ryu, 2016; Sappleton \& Lourenco, 2016, etc.) investigate time use for personal life and work in different ways. Yaniv (2011), Ratzel (2009) and other scientists highlight the lack of research about time allocation at theoretical and empirical levels in the economic context. An obvious example of this situation is the Harmonized European Time Use Survey (HETUS). HETUS is a time use survey. The sample is 15 European countries. The period was 1998-2006. In this case, there are the issue of updating data. This can be justified on the basis of Mrkic (2008). Scientist emphasized that data of time use (for different areas) by countries, should be updated at least every five years. On the other hand, this recommendation is not followed in the case of Lithuania. In fact, the latest HETUS statistics in Lithuania were collected in 2003. Hence, previously time use studies and time allocation data show that there is still a lack of the new time allocation statistics and analysis of it.

On the other hand, there are four main arguments that can be rationally justify the lack of time allocation studies because time allocation studies are: (1) sophisticated; (2) time-consuming; (3) knowledge-intensive; (4) receptive to human resources. These arguments are prepared based on Mrkic (2008), Sendi \& Brouwer (2004) other authors. It is important to note, that these systematized four arguments indicate Lydeka \& Tauraite (2018) too.

Although the time use studies are complex, however there are some advantages of these studies such as: (1) provide detailed information about persons' behaviour in macro level; (2) provide significant information about worklife balance; (3) indicate the impact of time allocation for separate parts of time for employed person's work and individual life; (4) show the time allocation impact on individual's health; (5) indicate time use impact on wages; (6) present important time allocation statistic and differences of it between genders; and other valuable social, economic and statistical information. Hence, the time use studies are comprehensive. Moreover, researchers can provide useful and meaningful statistical information for employed persons by developing, providing recommendations, and further discussing about time allocation for personal life and work.

In conclusion of theoretical background, it was found out that the basic theoretical principles of time allocation between personal life and work are revealed in the context of labourleisure (personal life) model, its formation assumptions and three main constraints (budget, time, environmental).

This paper assumes that model of labour-leisure (personal life) characterizes behaviour of a rational person when daytime is allocated to two main parts: work time and leisure time (for personal life). Differences in time allocation among employed people can be caused by gender differences.

So, the studies on time allocation are relevant and useful. On the other hand, the lack of theoretical and practical analysis of the field of time allocation has been identified. This case encourages to do further studies in time allocation topic by providing new empirical insights and also recommendations.

\section{The Methodology of Empirical Research of the Employed Population on Time Allocation for Work and Personal Life}

The purpose of empirical research - to analyse the results of time use among employed Lithuanian population in terms of gender in 2017 by determining the main differences and similarities in the researched population.

The logic structure of this research is based on an eightstep model by Kumar (2011). Two main methods: questionnaires and time diary were used for collecting the primary data. It is important to note, that the questionnaire and the time diary were compiled using the methodological recommendations of Eurostat (2009) for the realization of HETUS survey.

The purpose of individual questionnaire - consists of four main elements: (1) to find out the respondent's type; (2) to find out the basic needs and priorities; (3) to find out the statistics of current and desired wages; (4) to find out the general information about respondent.

The purpose of time diary - is to find out how long respondent devotes to eight-time allocation fields: (1) sleep; (2) other physiological needs (eating; personal hygiene, etc.); (3) work; (4) science / studies; (5) housework and childcare; (6) leisure time (in the narrow sense); (7) travelling; (8) other activities.

Employed Lithuanian people (406 respondents; 4.9 percent was a sample error) were interviewed from January 3th to March 5th in 2017. In this article employed person is understood as person aged 15 and over who work and receive an appropriate wage or profit share. This definition is provided by the Department of Statistics of the Republic of Lithuania (2016). It is important to note, that this methodology was also used in the research by Lydeka, Tauraite (2018). 
Research hypothesis. The hypothesis has been formulated to identify the differences between woman and men in their leisure time (narrow sense). The Stjudent $t$ criterion for independent samples is used to implement the hypothesis. The dependent variable (leisure time; in the narrow sense) is measured by the ratio, and the independent variable (gender) by the name scale. The planned significance level was 0.05 , but the actual one was 0.049 .

$\mathrm{HI}_{1}$ : on average, men spend more time on leisure (in the narrow sense) than women do.

Statistical hypothesis (see formula 1 ):

$$
\left\{\begin{array}{l}
H 1_{0}: \mu_{m}-\mu_{w}=0, \\
H 1_{1}: \mu_{m}-\mu_{w} \neq 0 .
\end{array}\right.
$$

Hypothesis acceptance conditions: $H l_{l}$ hypothesis is confirmed if time data (for men and women) allocated for leisure time (in narrow sense) is distributed according to normal distribution, when Kolmogorov-Smirnov's test $\mathrm{p}>$ 0.05 and average time allocated for leisure (in narrow sense) dispersions are statistically significantly different and the time allocated to leisure (in the narrow sense) by men $\left(\mu_{\mathrm{m}}\right)$ is higher than the time allocated to leisure by women $\left(\mu_{\mathrm{w}}\right)$.

Correlation analysis. Three cases of correlation analysis were carried out in the analysis of time allocation for personal life and work:

1) between monthly net wage and average time spent on work (using Spearman correlation coefficient);
2) between the monthly net wage and the average time spent on leisure (in the narrow sense; the Spearman correlation coefficient is applied);

3 ) between average time spent on sleep and work (Pearson correlation coefficient is applied).

\section{Empirical Results of Research on Time Allocation for Work and Personal Life among Employed Population in Terms of Gender}

In this section of the article, information on priorities, goals and differences between these groups in general and by gender is given first. Secondly, the current wages of employed population in Lithuania in general and by gender are reviewed. It is followed by a detailed analysis of the time use into eight key areas by employed population in Lithuania in general and by gender. In this economic analysis, correlation analysis is also carried out in order to do more precisely investigate the time allocation behaviour of the employed Lithuanians. The research and its results provide an opportunity to identify the main differences and similarities in time use among employed Lithuanians in general and in terms of gender.

Priorities of employed people. The three most important priorities of the employed population are: work $(67.5 \%)$, housework and childcare $(59.1 \%)$ and sleep (56.7\%; see Table 1).

Table 1

\begin{tabular}{|c|c|c|c|}
\hline Employed Persons & Total $(\%)$ & $\operatorname{Men}(\%)$ & Women $(\%)$ \\
\hline Sleep & 56,7 & 57,8 & 55,6 \\
\hline Other physiological needs & 41,1 & 38,7 & 43,5 \\
\hline Work & 67,5 & 66,8 & 68,1 \\
\hline Science / study & 9,6 & 10,6 & 12,8 \\
\hline Housework and childcare & 59,1 & 55,3 & 62,8 \\
\hline Leisure & 39,4 & 41,7 & 37,2 \\
\hline Travel & 4,7 & 3,0 & 6,3 \\
\hline Material well-being & 45,6 & 41,2 & 49,8 \\
\hline Sum & 323,6 & 315,1 & 336,0 \\
\hline
\end{tabular}

The Allocation of the Priorities of the Employed Persons in Lithuania (According to Empirical Survey Data)

Note: leisure time is analysed here in a narrow sense. The sum total is more than 100 percent because respondents were given an option to choose more than one answer.

The key priorities identified coincide with the ranking of the eight needs of the employed population (from the most important to the least important): work, housework and childcare, sleep, other physiological needs, material wellbeing, leisure (in the narrow sense), travel, science / study (see Table 2).

\begin{tabular}{|c|c|c|c|c|c|c|c|}
\hline $\begin{array}{ll}\text { Priorities } & \text { Employed Persons } \\
\end{array}$ & $\stackrel{\substack{0 \\
:}}{:}$ & Total $(\%)$ & 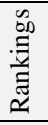 & $\operatorname{Men}(\%)$ & 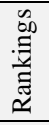 & Women $(\%)$ & 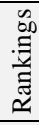 \\
\hline Work & 1 & 30,5 & 1 & 31,7 & 1 & 29,5 & 4 \\
\hline Housework and childcare & 2 & 21,9 & 2 & 23,1 & 1 & 21,3 & 2 \\
\hline Sleep & 3 & 20,0 & 3 & 23,1 & 4 & 18,4 & 1 \\
\hline Other physiological needs & 4 & 22,9 & 4 & 24,6 & 4 & 21,3 & 4 \\
\hline Material well-being & 5 & 21,7 & 5 & 23,6 & 5 & 19,8 & 1 \\
\hline Leisure & 6 & 30,3 & 6 & 27,1 & 6 & 33,3 & 6 \\
\hline Travel & 7 & 59,1 & 7 & 56,8 & 7 & 61,4 & 7 \\
\hline \multirow{2}{*}{ Science / study } & 8 & 86,7 & \multirow{2}{*}{8} & \multirow{2}{*}{85,9} & \multirow{2}{*}{8} & \multirow{2}{*}{87,4} & \multirow{2}{*}{8} \\
\hline & [3] & {$[25,4]$} & & & & & \\
\hline Sum & - & 293,1 & - & 295,9 & - & 292,4 & - \\
\hline
\end{tabular}

Ranking of Needs of Employed Persons in Lithuania (According to Empirical Survey Data)

Note: leisure time is analysed here in a narrow sense. The square brackets contain information about all employed students. The percentages are based on the distribution of responses to each need, so the amount exceeds 100 percent. 
It has been found that women often prioritize work; housework and childcare (see Table 2). On the other hand, based on the identified key priorities, it can be concluded that for women meeting the need for work $(68.1 \%)$ is more important than meeting the need for housework and childcare $(62.8 \%$; see Table 1$)$. This may be linked to the increasing integration of women into the labour market. For men, work is also a top priority (ranked - 1 most frequently; see Table 2). In summary, it can be said that in most cases, men and women prioritize work.

The salary of employed persons. In 2017, employed people in general (29.6\%) and also by gender (men $30.2 \%$, women $29.0 \%$ ) most frequently show total monthly net wage in the range of $€[419 ; 519]$ (see Table 3).

Table 3

Distribution of Monthly net Wages of Employed Lithuanians in 2017 (Based on Empirical Survey Data)

\begin{tabular}{|c|c|c|c|}
\hline Interval of wage & Total & Men & Women \\
\hline$\leq € 317$ & $8,1 \%$ & $6,5 \%$ & $9,7 \%$ \\
\hline$€[318 ; 418]$ & $14,3 \%$ & $15,6 \%$ & $13,0 \%$ \\
\hline$€[419 ; 519]$ & $29,6 \%$ & $30,2 \%$ & $29,0 \%$ \\
\hline$€[520 ; 616]$ & $24,9 \%$ & $23,6 \%$ & $26,1 \%$ \\
\hline$€[617 ; 874]$ & $17,7 \%$ & $17,6 \%$ & $17,9 \%$ \\
\hline$€[875 ; 2090]$ & $4,4 \%$ & $5,0 \%$ & $3,9 \%$ \\
\hline$\geq € 2091$ & $1,0 \%$ & $1,5 \%$ & $0,5 \%$ \\
\hline Sum & $100,0 \%$ & $100,0 \%$ & $100,0 \%$ \\
\hline
\end{tabular}

Thus, it can be argued that there is no discrimination between both sexes: women and men in the context of wages.
Actual time allocation of employed population. It was found that on average employed Lithuanians allocate 24.7 percent of time on work, and 75.3 percent of the time - on personal life (see Figure 1).

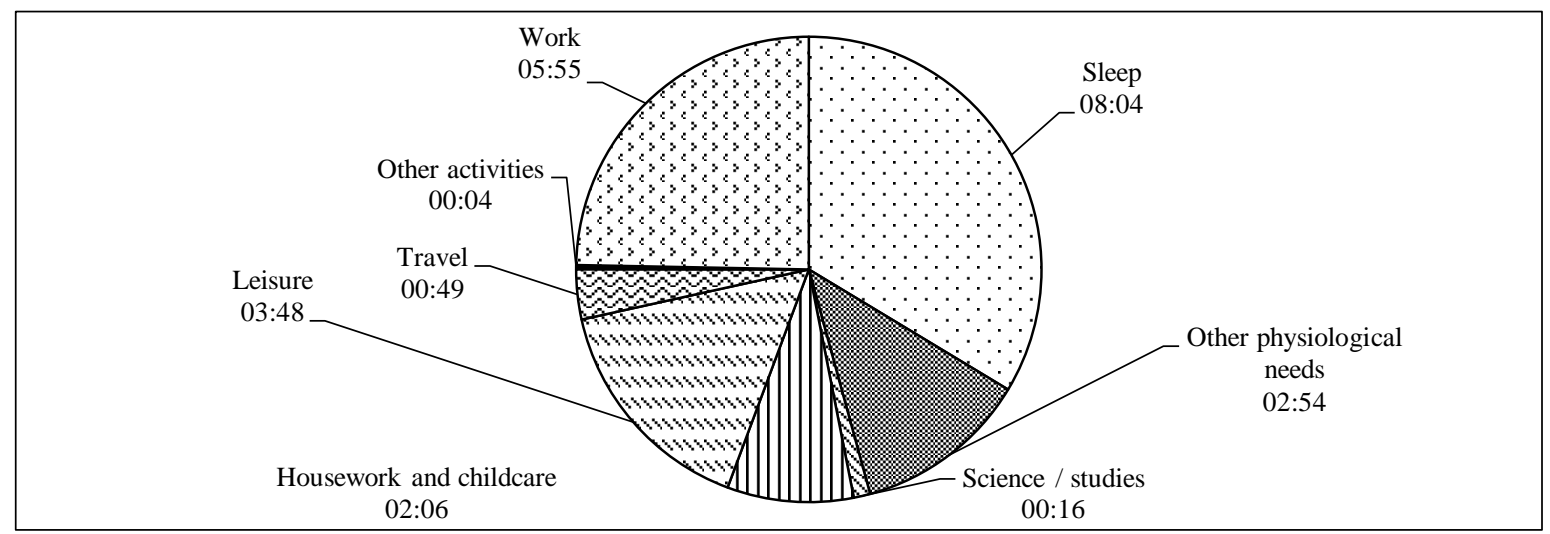

Figure 1. The Allocation of Time per Day (24 hours) Among Employed Population in Lithuania (in General) in 2017 (According to the Data of the Time Diary of the Empirical Study)

Note: leisure time is analysed here in a narrow sense. Time is given in minutes, so there may be 00:01 hrs. error.

There can be highlighted three main areas in personal life by employed people in the context of time allocation: (1) sleep (08:04 hrs.); (2) leisure (in the narrow sense, 3:48 hrs.); (3) other physiological needs (e.g., personal hygiene; eating, etc., 02:54 hrs.; see Figure 1). The least amount of time during the day is allocated to these areas of time: other activities (00:04 hrs.); science / studies (00:16 hrs.).

In the study of the male population, it is observed that approximately 24.4 percent per day ( 24 hours) is allocated to work and 75.6 percent on personal life (see Figure 2).

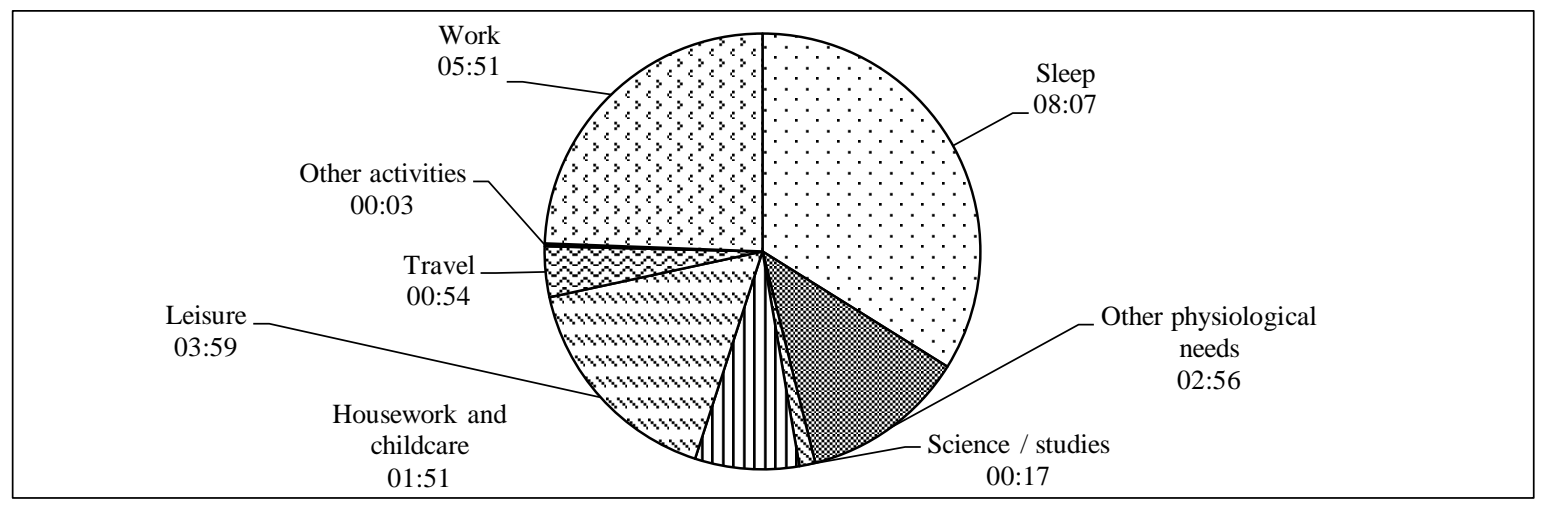

Figure 2. The Allocation of Time per Day (24 hours) Among Employed Lithuanian Males in 2017 (According to the Data of the Time Diary of the Empirical Study)

Note: leisure time is analysed here in a narrow sense. Time is given in minutes, so there may be 00:02 hrs. error. 
There can be highlighted three main areas in personal life by men in the context of time allocation: (1) sleeping (8:07 hrs.); (2) leisure (in the narrow sense; 3:59 hrs.); (3) other physiological needs (2:56 hrs.; see Figure 2). The least amount of time during the day is spent on these two time areas: other activities (00:03 hrs.) and science / studies (00:17 hrs.).

Analysing the peculiarities of women's time use in Lithuania, it was found that 24.9 percent of the time was allocated to work per day and 75.1 percent on personal life (see Figure 3).

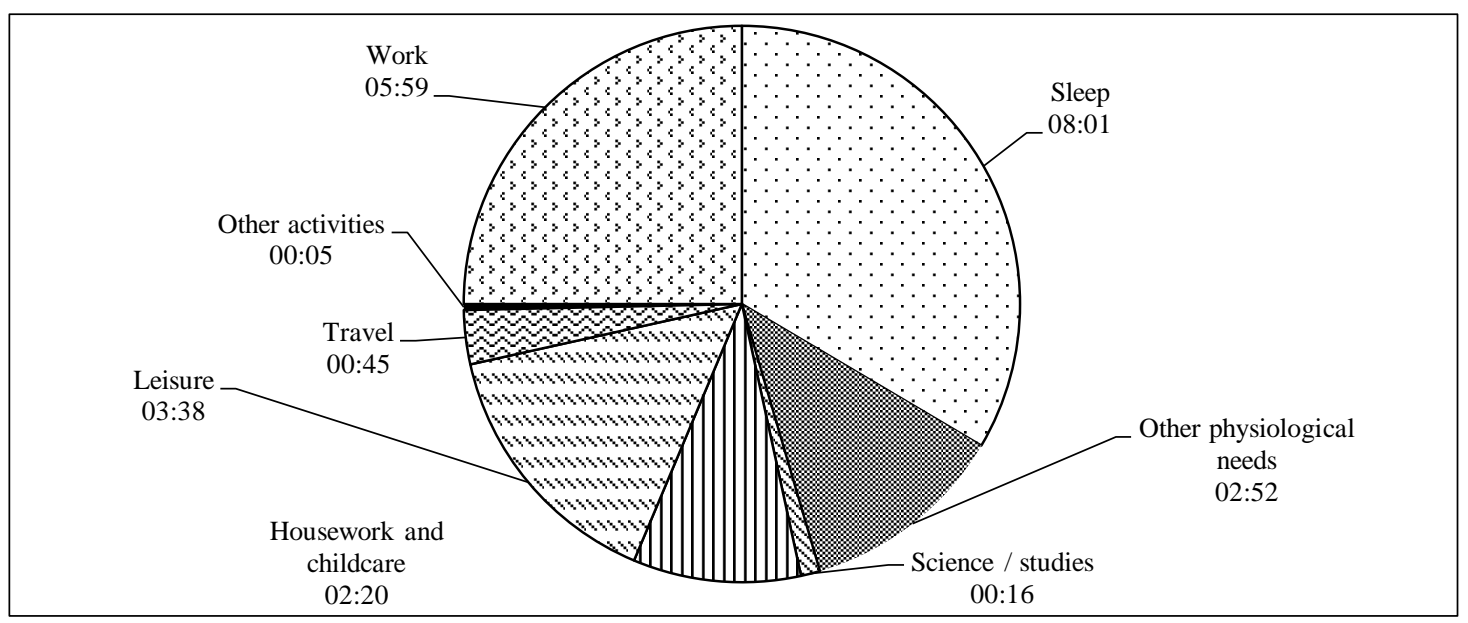

Figure 3. The Allocation of Time per Day (24 Hours) Among Employed Lithuanian Women in 2017 (According to Empirical Time Diary Data)

Note: leisure time is analysed here in a narrow sense. Time is given in minutes, so there may be 00:04 hrs. error.

There can be highlighted three main areas in personal life by women in the context of time allocation: (1) sleeping (8:01 hrs.); (2) leisure (in the narrow sense; 3:38 hrs.); (3) other physiological needs (2:52 hrs.; see Figure 3). The least amount of time during the day is spent on these two time areas: other activities (00:05 hrs.) and science / studies (00:16 hrs.).

In summary, both men and women spend relatively most of their time in the areas of personal life, sleeping, leisure (in the narrow sense), and other physiological needs.

Time for work and personal life. A correlation analysis was performed to determine the existing / non-existing relationship between time allocated for work and net monthly salary. It was found that with 95.1 percent probability between monthly net wages and average time allocated to work, there exists a statistically significant $(\mathrm{p}<0.049)$ but weak $(\rho=0.231)$ positive relationship. The results coincide with Borghans et al. (2014) research: in Germany in 2014 there was a positive link between the wages earned and the time spent for work. The conclusions of study by scientists Hamermesh \& Slemrod (2005), which coincide with the results of this study, should also be emphasized.

The differences in time allocation for personal life and work between men and women are relatively small: men devote an average of 0.5 percentage points more daily to their personal lives than women, and women spend on average more than 0.5 percentage points of time on work daily than men (see Figure 2, 3). The results of this kind, which reveal that women work relatively longer than men, are supported by Brunnich et al. (2005), and OECD (2011). Opposite findings are identified by representatives of International Labour Office (2011), Snir \& Harpaz (2006). These results of different nature encourage further analysis of time allocation between genders. Nevertheless, the results of this study reveal the fact that men devote a relatively larger amount of time to personal life than women, and women - to work.

Time for sleep and other physiological needs. It was found that in 2017 employed Lithuanians allocated 33.6 percent on average for sleep and 45.7 percent for other physiological needs daily ( 24 hours; see Figure 1 ). The time spent by employed population on sleep corresponds to the recommendations of researchers Hirshkowitz et al. (2015): people aged 18-64 should sleep at least 7:00, but not more than 9:00 hours per day.

Minor differences between both sexes: women and men are noticeable in the time spent on sleep and other physiological needs. That is, men spend 0.4 percentage points more time on sleep than women do, and men spend 0.3 percentage points more time on other physiological needs than women do (see Figure 2, 3). Taking into account the men's and women's ranking scale of meeting needs (see Table 2 ), it can be concluded that the need for sleep is more important for men than for women. It is believed that this is why men spend more time on sleep than women do. In the study of the female population, it was found that women were sleeping shorter and working longer (daily) than men. A correlation analysis was performed to identify the relationship between these two time division domains. It was found that with 95.1 percent probability there is a statistically significant $(p<0.049)$ but weak $(\rho=-0.385)$ negative relationship between the average time spent on work and sleep. Williams (2008) also notes the importance of sleeping time, especially in seeking to balance work and personal time. In this case, sleep time is reduced most commonly when additional time is required for other activities.

Time for science / studies. Employed Lithuanians allocated 1.1 percent on average for science / studies in 2017 (see Figure 1). A rational explanation for the relatively short 
duration for science / studies compared to other time allocation areas can be explained considering identified needs' order of satisfaction. It has been found that the priority of science / studies among the 8 areas of time allocation in all cases (in general, by gender) is indicated as the last need, i.e. 8th place (see Table 2). On the other hand, the allocation of time to science / studies among employed students is different. Employed students are averaging 5.3 percent of daily time for science / studies (priority of science / studies - 3rd place). Analysing the time spent on science / studies on gender, there are no significant differences.

Time for housework and childcare. The average time spent on housework and childcare among employed Lithuanians was 8.8 percent in 2017 (see Figure 1). There are noticeable differences in time allocation between women and men: women spend 2.0 percentage points more time on housework and childcare than men do (see Figure 2, 3). This can be attributed to the needs ranking: women often place the need for housework and childcare in the $1^{\text {st }}$ place (along with work) and men in the $2^{\text {nd }}$ place (see Table 2). The results of this study coincide with the time use in the Netherlands - men spend less time on housework and child care than women do (Gimenez-Nadal \& Molina, 2015). Through a more detailed analysis, it would be possible to test the hypothesis if the time spent for housework and childcare would be related to the number of children in the family, family situation, and so on. This would provide more in-depth conclusions and recommendations for the employed population. Nevertheless, according to the results of this study, it was found that married people spend 14.3 percentage points more time on housework and childcare than all employed persons. In addition, interesting findings have been made by researchers Chen et al. (2015) investigating the German labour market: the more time parents spend on work, the less time parents spend on children.

Time for leisure (in the narrow sense). Employed Lithuanians on average allocated 15.8 percent of daily time on leisure in 2017 (see Figure 1). The correlation analysis has revealed that with 95.1 percent probability in employed population between monthly net wages and leisure (in the narrow sense) there exists a statistically significant ( $\mathrm{p}<$ $0.049)$ but negative $(\rho=-0.104)$ very weak correlation. This means that the more time employed persons allocate to their leisure time (in the narrow sense; daily), the lower monthly net wage is received (or vice versa; the direction in this study was not determined). Cavagnoli (2008) received the results of the opposite relationship between the variables.

When focusing the attention on men and women and their leisure (in the narrow sense), it was revealed that the results of this paper coincide with those of Galvez-Munoz et al. (2011): women spend less time on leisure (in the narrow sense) than men do. Specifically, it was found that men in Lithuania spend by 1.4 percentage points more time on leisure (in the narrow sense) than women (see Figure 2, 3 ) do. These differences can be explained by differences in the amount of time spent for personal life (men devote more time to personal life than women do), where leisure (in the narrow sense) is one of its components. Analysing the differences in the use of time spent on leisure (narrow sense) between men and women, it was found that the $H 1_{0}$ hypothesis was rejected. So, the alternative hypothesis $H 1_{l}$ was accepted. This is because with 95.1 percent of probability it is determined that men devote more time to leisure (in the narrow sense) than women $\left(\mathrm{Hl}_{l}\right.$ is confirmed) do. In summary, it can be concluded that employed men in Lithuania in 2017 spent more time on leisure (in the narrow sense) than women did.

Time for travel and other activities. Employed Lithuanians allocated 3.4 percent on travel and 0.3 percent on other activities on average in 2017 (see Figure 1). Relatively large differences between both sexes: women and men in travel and other activities are not noticeable: men 00:09 hrs. more time spend on travel than women do, but women 00:02 hrs. devote more time to other activities than men do (see Figure 2, 3). These similarities with respect to travel time can also be justified based on gender prioritization: men and women rank travel as priority number 7 (see Table 2).

Summarizing the analysis of the time use of employed population in Lithuania in general and in terms of gender, eleven main conclusions can be drawn (the order is presented in random order). First, work is the top priority for the employed population in general and by gender. Second, the monthly net wage during the research period is the same among the employed population in general and by gender. Third, a weak, positive relationship between monthly net wage and the average time spent for work is identified. Fourth, the employed population in Lithuania devotes more time for personal life than to work. In terms of gender, women spend more time on work, and men spend more time on their personal lives. Fifth, there are rational differences in time use between both sexes: women and men in terms of sleep and other physiological needs. Sixth, a weak, negative relationship between work and sleep time is identified. Seventh, employed students in Lithuania devote more time to science / studies than non-learners. Eighth, women spend more time for housework and childcare than men do on average. Ninth, a very weak, negative relationship is observed between the net monthly earnings and the time spent on leisure (in the narrow sense). Tenth, men devote more time to leisure time in Lithuania (in the narrow sense) than women do. Eleventh, men spend more time on travel than women do, and women spend more time on other activities.

\section{Conclusions}

In the article, the authors analysed the main theoretical principles of time use for personal life and work. The analysis of theoretical background showed that the time structural can be divided into these basic parts: (1) work time (time for paid work); (2) personal life time. The labourleisure (personal life) model is the context where these two time areas play the main role.

The review of the previous time use researches showed that the time allocation topic is relevant and important. However, the lack of such type studies was identified in the theoretical and practical levels, especially in the case of Lithuania. All these aspects justify the importance and meaningful of this paper.

Methodological part of this study describes the methods of empirical data collection, methodical assumptions, research hypothesis, and description of correlation analysis. The population of the survey was Lithuanian employed 
people. Data were collected using two basic techniques: (1) questionnaire; (2) time diary.

The research carried out showed that the most important priority for men and women in Lithuania is work. Discrimination in monthly net wages between men and women is not noticeable. This kind of conclusion is based on the fact that the monthly net wages are usually the same and fall within the range $[419 ; 519]$ euros.

When analysing the peculiarities of time allocation between both sexes: men and women in Lithuania, it was found that women spend relatively more time for work, and men - on personal life. Differences are also noticeable in the time spent on sleep and other physiological needs. Men spend more time for sleep and other physiological needs than women do. On the other hand, significant differences were not identified in the time spent on science / studies. It is understood that the time use differences exist between genders when examining the daily time spent on housework and childcare. In this case, women spend more time on this time division than men do. However, it should be noted that men spend relatively more time on leisure (in the narrow

\section{References}

Aguiar, M., \& Hurst, E. (2007). Measuring Trends In Leisure: The Allocation Of Time Over Five Decades. Quarterly Journal of Economics, 122(3), 969-1006. https://doi.org/10.1162/qjec.122.3.969

Alesina, A. F., Glaeser, E. L., \& Sacerdote, B. (2006). Work and Leisure in the U.S. and Europe: Why So Different? National Bureau of Economic Research Macroeconomics Annual, 20, 1-99. https://doi.org/10.1086/ma.20.3585411

Bauer, F., Groß, H., Oliver, G., Sieglen, G., \& Smith, M. (2007). Time use and work-life balance in Germany and the UK. Report. Available from internet: http://www.agf.org.uk/cms/upload/pdfs/R/2007_R1453_e_time_use_and_worklife_balance.pdf

Becker, G. S. (1965). A Theory of the Allocation of Time. The Economic Journal, 75(299), 493-517. https://doi.org/10. $2307 / 2228949$

Borghans, L., Collewet, M., \& Seegers, P. (2014). Measuring preference for leisure using hypothetical choices. Available from internet: http://www.parthen-impact.com/parthen-uploads/78/2015/add_1_258830_EfL7NuttU0.pdf

Brunnich, G., Druce, P., Ghissassi, M., Johnson, M., Majidi, N., Radas, A. L., Riccheri, P. R., De Sentenac, C., \& Vacarr, D. (2005). Three Case Studies of Time Use Survey Application in Lower and Middle-Income Countries. Available from internet: http://www.levyinstitute.org/undp-levy-conference/papers/paper_Vacarr.pdf

Caragea, N. (2009). Time Allocation in Economics and the Implications for Economic Development. Revista Romana de Economie, 28(2), 1-19.

Cavagnoli, D. (2008). Addiction to Work: An Inelastic Wage Elasticity of Labour Supply Equals Long Hours of Work. Australian Journal Of Labour Economics, 11(2), 129-147.

Chen, S. E., Moser, A., \& Nayga, R. M. (2015). Too Busy to Eat with the Kids? Parental Work and Children's Eating, Applied Economic Perspectives and Policy, 37(3), 347-377. https://doi.org/10.1093/aepp/ppv001.

Colella, F., \& Van Soest, A. (2013). Time use, consumption expenditures and employment status: evidence from the LISS panel. Paper presented at the 2013, 7th MESS Workshop, Den Haag.

Dagsvik, J. K., Jia, Z., Kornstad, T., \& Thoresen, T. O. (2012). Theoretical and practical arguments for modeling labor supply as a choice among latent jobs. Discussion Papers, No. 692, 1-25. https://doi.org/10.1111/joes.12003

Department of Statistics of the Republic of Lithuania (2016). Employment and unemployment: Metainformation. Available from internet: http://osp.stat.gov.lt/documents/10180/0/uzimtumas_metainfo

Douglas, E. J., \& Morris, R. J. (2006). Workaholic, or just hard worker? Career Development International, 11(5), 394417. https://doi.org/10.1108/13620430610683043.

Eurostat (2009). Harmonised European time use surveys - 2008 Guidelines. Available from internet: http://ec.europa.eu/eurostat/ramon/statmanuals/files/KS-RA-08-014-EN.pdf

Fernandez-Crehuet, J. M., Gimenez-Nadal, J. I., \& Recio, L. E. R. (2016). The National Work-Life Balance Index $\mathrm{C}:$ The European Case. Social Indicators Research, 128(1), 341-359. https://doi.org/10.1007/s11205-015-1034-2 
Forris, S. E. (2015). The Quest for Work and Family Balance Using Flexible Work Arrangements (doctoral dissertation). Available from internet: https://scholarworks.waldenu.edu/cgi/viewcontent.cgi?referer=https://www.google.com/\& httpsredir=1\&article $=2438 \&$ context=dissertations

Fortin, B., Jacquemet, N., \& Shearer, B. (2010). Labour Supply, Work Effort and Contract Choice: Theory and Evidence on Physicians. IZA Discussion Papers, No. 5188. https://doi.org/10.2139/ssrn.1682101

Galvez-Munoz, L., Rodriguez-Modrono, P., \& Dominguez-Serrano, M. (2011). Work and Time Use By Gender: A New Clustering Of European Welfare Systems. Feminist Economics, 17(4), 125-157. https://doi.org/10.1080/135 45701.2011.6209757

Gimenez-Nadal, J. I., \& Molina, J. A. (2015). Commuting Time and Household Responsibilities: Evidence Using Propensity Score Matching. IZA Discussion Papers, No. 879. https://doi.org/10.1111/jors.12243

Hamermesh, D. S., \& Slemrod, J. (2005). The Economics of Workaholism: We Should Not Have Worked on This Paper. IZA Discussion Papers, No. 1680. https://doi.org/10.3386/w11566

Hamermesh, D. S., \& Stancanelli, E. (2015). Long Workweeks and Strange Hours. Industrial and Labor Relations Review, 68(5), 1007-1018. https://doi.org/10.1177/0019793915592375

Hawrylyshyn, O. (1977). Towards A Definition Of Non-Market Activities. Review Of Income \& Wealth, 23(1), 79-96. https://doi.org/10.1111/j.1475-4991.1977.tb00005.x

Hirshkowitz, M., Whiton, K., Albert, S. M., Alessi, C., Bruni, O., DonCarlos, L., Hazen, N., Herman, J., Katz, E. S., Kheirandish-Gozal, L., Neubauer, D. N., O'Donnell, A. E., Ohayon, M., Peever, J., Rawding, R., Sachdeva, R. C., Setters, B., Vitiello, M. V., Ware, J. C., \& Hillard, P. J. A. (2015). National Sleep Foundation's sleep time duration recommendations: methodology and results summary. Sleep Health: Journal of the National Sleep Foundation, 1(1), 40-43. https://doi.org/10.1016/j.sleh.2014.12.010

International Labour Office (2011). Work-life balance. Available from internet: http://www.ilo.org/wcmsp5/groups/public/ -ed_norm/---relconf/documents/meetingdocume nt/wcms_163642.pdf

Jankiewicz, J. (2015). Time allocation of people not working in the market: how does unemployment differ from economic inactivity in Central Eastern Europe? Journal of International Studies, 8(3), 201-209. https://doi.org/10.14254/20718330.2015/8-3/16.

Kabukcuoglu, A., \& Martinez-Garcia, E. (2016). The market resources method for solving dynamic optimization problems. Globalization and Monetary Policy Institute Working Paper, No. 274. https://doi.org/10.24149/gwp274

Kalenkoski, C. M., Hamrick, K. S. (2013). How Does Time Poverty Affect Behavior? A Look at Eating and Physical Activity, Applied Economic Perspectives and Policy, 35(1), 89-105. https://doi.org/10.1093/aepp/pps034

Krueger, A. B., \& Mueller, A. I. (2012). Time Use, Emotional Well-Being, and Unemployment: Evidence from Longitudinal Data. American Economic Review: Papers \& Proceedings, 102(3), 594-599. https://doi.org/10.1257/ aer.102.3.594

Kumar, R. (2011). Research Methodology A Step-by-Step Guide for Beginners. Third Edition. London: Sage.

Laeeque, S. H. (2014). Role of Work-Family Conflict in Job Burnout: Support from the Banking Sector of Pakistan. International Letters of Social and Humanistic Sciences, 40, 1-12. https://doi.org/10.18052/www.scipress.com/ ILSHS.40.1

Lee, S., McCann, D., \& Messenger, J. C. (2007). Working Time Around the World: Trends in working hours, laws and policies in a global comparative perspective. London and Geneva: Routledge and ILO.

Lydeka, Z., \& Tauraite, V. (2018). Modeling Optimal Time Allocation for Work and Personal Life at The National Level (Case in Lithuania). Journal of Social Science Research, 13, 2897-2912. https://doi.org/10.24297/jssr.v13i0.7973

Manski, C. F. (2014). Identification of Income-Leisure Preferences and Evaluation of Income Tax Policy. Quantitative Economics, 5(1), 145-174. https://doi.org/10.3982/QE262

Mezey, E. W., \& Conrad, J. M. (2010). Real Options in Resource Economics. Annual Review of Resource Economics, 2(1), 35-52. http://dx.doi.org/10.1146/annurev-resource-040709-135122

Mrkic, S. (2008). Time Use Statistics in the Context of Social Statistics. Available from internet: https://millenniumindicators.un.org/unsd/statcom/statcom_08_events/special\%20events/New_directions_social/Srdj an_Mrkic_Time_Use_Paper.pdf

Myck, M., \& Reed, H. (2006). A Review Of Static And Dynamic Models Of Labour Supply And Labour Market Transitions. Working Paper 06/15

OECD (2011). How's life? Measuring well-being. Paris: OECD Publishing. https://doi.org/10.1787/9789264121164-en

Ratzel, S. (2009). Revisiting the neoclassical theory of labour supply - Disutility of labour, working hours, and happiness. Faculty of Economics and Management Magdeburd Working Paper Series, No. 5, 1-28. 
Zigmas Lydeka, Viktorija Tauraite. Evaluation of the Time allocation for Work and Personal Life Among Employed...

Ryu, G. (2016). Public Employees' Well-Being When Having Long Working Hours and Low-Salary Working Conditions. Public Personnel Management, 45(1), 70-89. https://doi.org/10.1177/0091026015601143

Sappleton, N., \& Lourenco, F. (2016). Work satisfaction of the self-employed: The roles of work autonomy, working hours, gender and sector of self-employment. The International Journal of Entrepreneurship and Innovation, 17(2), 89-99. https://doi.org/10.1177/1465750316648574

Sendi, P., \& Brouwer, W. (2004). Leisure time in economic evaluation: theoretical and practical considerations. Expert Review of Pharmacoeconomics \& Outcomes Research, 4(1), 1-3. https://doi.org/10.1586/14737167.4.1.1

Snir, R., \& Harpaz, I. (2006). The workaholism phenomenon: a cross-national perspective. Career Development International. 11(5), 374-393. https://doi.org/10.1108/13620430610683034

Wei, X., Qu, H., \& Ma, J. E. (2009). A Neoclassic Growth Model of Leisure Time and China's Economic Growth. Available from internet: http://scholarworks.umass.edu/cgi/viewcontent.cgi?arti cle=1043\&context=refereed

Yaniv, G. (2011). Workaholism and marital estrangement: A rational-choice perspective. Mathematical Social Sciences, 61(2), 104-108. https://doi.org/10.1016/j.mathsocsci.2010.11.006

The article has been reviewed.

Received in March 2019; accepted in February 2020. 